\title{
Integrated Treatment Programmes for Mothers with Substance Use Problems: A Systematic Review and Meta-analysis of Interventions to Prevent Out-of-home Child Placements
}

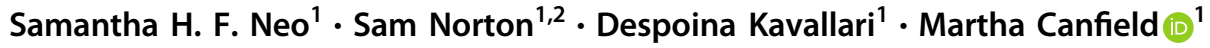 \\ Accepted: 3 September 2021 / Published online: 16 September 2021 \\ (c) The Author(s) 2021
}

\begin{abstract}
Approximately half of mothers receiving substance use treatment are involved with childcare proceedings. This review aims to determine whether integrated treatment programmes for mothers with substance use problems are effective in preventing out-ofhome placement (temporally/permanent) and influencing other maternal factors such as patterns of substance use, treatment completion and parenting behaviours. Six trials were identified-two randomised controlled trials and four non-randomised controlled studies. The pooled sample of participants was 1717. The results showed that mothers who participated in integrated treatment programmes were significantly less likely to have the children removed from their care (Odds Ratio $(O R)=0.40,95 \%$ CI $=0.27,0.61)$, more likely to complete substance use treatment $(O R=3.01,95 \% \mathrm{CI}=1.79,5.06)$, and more likely to reduce their alcohol consumption (Standardised Mean Difference $(S M D)=-0.40,95 \% \mathrm{Cl}=-0.78,-0.01)$ and drug use $(S M D=-0.30$, $95 \% \mathrm{CI}=-0.53,-0.07)$. However, non-significant reductions were observed for parent-child conflict $(S M D=-0.35,95 \% \mathrm{CI}=$ $-0.72,0.03)$ and child abuse risk $(S M D=-0.03,95 \% \mathrm{CI}=-0.36,0.31)$. While the findings from this review suggest that mothers involved in integrated treatment programmes could potentially be less likely to experience out-of-home child placements and more likely to improve substance use treatment outcomes, little evidence exists for the effectiveness of these interventions. Further research, particularly high-quality RCTs, is required to demonstrate and persuade health and public policy on the farreaching value of the integrated approaches.
\end{abstract}

Keywords Out-of-home child placement, Mothers, Substance use, Integrated treatment programmes, Meta-analysis

\section{Highlights}

- First systematic review exploring the effectiveness of integrated treatment programmes for mothers with substance use problems on out-of-home child placements.

- A lack of studies was found, despite broad inclusion criteria.

- Presently integrated treatment programmes are being utilised with unclear or unsupported benefit from a scientific standpoint.

- Integrated treatment programmes produce favourable outcomes in preventing out-of- home child placements, treatment completion and maternal substance use.

- More high-quality effectiveness studies are required to demonstrate and persuade health and public policy on the farreaching value of the integrated approaches.

Supplementary Information The online version contains supplementary material available at https://doi.org/10.1007/s10826021-02099-8.

Martha Canfield

Martha.canfield@kcl.ac.uk

1 Department of Psychology, Health Psychology Section, Institute of Psychiatry, Psychology and Neuroscience, King's College

\section{Introduction}

The prevalence of substance use among mothers who are involved in childcare proceedings is high and is related to

London, London, UK

2 Department of Inflammation Biology, Faculty of Life Sciences and Medicine, King's College London, London, UK 
negative child placement outcomes, such as lower rates of reunification, higher rates of out-of-home placement, greater risk of re-entry into the child welfare system and permanent loss of parental rights (Green et al., 2007; Taplin \& Mattick, 2015; Tracy, 1994; Tsantefski et al., 2014). An estimated $50 \%$ to $80 \%$ of childcare proceeding cases across the world involved mothers with substance use problems (Harp \& Oser, 2016; Public Health England, 2018; Taplin \& Mattick, 2013) and approximately 50\% of mothers in substance use treatment services have experienced the loss of the care of at least one of their children (Porowski et al., 2004; Tsantefski et al., 2014). However, the relationship between maternal substance use and child removal is not straightforward, with substance use rarely being the only contributor to the relationship (Wall-Wieler et al., 2018).

Mothers who use substances and are involved in the child welfare system tend to have multiple and complex needs, which include mental health comorbidities (Williams et al., 2011), trauma histories (Gilchrist \& Taylor, 2009), poor parenting skills (Canfield et al., 2017; Forrester \& Harwin, 2007), intimate partner violence victimisation (Canfield et al., 2021; Chowdry, 2018; Tsantefski et al., 2014), low social support (Sarkola et al., 2007), and deprived socioeconomic status (Basnet et al., 2015; Doab et al., 2015). There is also extensive evidence suggesting that the mothers' ability to care for their children tends to deteriorate in the context of these multiple needs (Canfield et al., 2017). This in turn has been associated with an increased risk of child abuse and/or neglect of their children (Nair et al., 2003).

In recent years, there has being a growing emphasis towards understanding how social and psychological characteristics of the mothers can interact with substance use to influence child abuse (Berger, 2005; Grella et al., 2006; Magura \& Laudet, 1996). Within this, research has found that well-integrated treatment approaches, which comprehensively address the individualised factors that lead to substance use and child abuse, were key in improving maternal and child outcomes (Marsh \& Cao, 2005). For instance, the use of multidisciplinary integrated treatment programmes, which include substance use treatment with interventions for maternal well-being (e.g., medical and nutrition-, mental health-, psychological-, parenting services; education and employment assistance), as well as other services (e.g., case management-, child-related services) (Marsh et al., 2011), revealed better parenting behaviours, such as improved parent-child interaction and lower child abuse risk, higher substance use treatment retention and reduction of maternal substance use, when compared with those who attended non-integrated treatment programmes or substance use treatment-as-usual (Milligan et al., 2010, 2011; Moreland \& McRae-Clark, 2018; Niccols et al., 2012a). A systematic review by Niccols et al. (2012b) also showed positive association between integrated treatment programmes for mothers with substance use problems and the improvements in their child development, physical growth (e.g., length, weight, and head circumference), emotional and behavioural functioning. The provision of comprehensive interventions or targeted services within an integrated treatment programme appears to fulfil the dynamic needs of the mothers (Sword et al., 2009), therefore suggesting that integrated treatment programmes may be more effective for mothers with substance use problems and their children, as compared to single-focus interventions (Lieberman, 1998; McHugh et al., 2010).

Even though research on integrated treatment programmes has shown promising findings, a majority of the studies focused on clinical outcomes, such as patterns of substance use, parenting behaviours or child behaviours (Dutra et al., 2008; Messina et al., 2015; Niccols et al., 2012a, 2012b). There appears to be a lack of emphasis on the practical outcomes of such interventions, for instance, the mitigation of the mothers' involvement in childcare proceedings (Canfield et al., 2017). Important work has been carried out to evaluate the effectiveness of integrated family dependency treatment courts (Harwin et al., 2018; Zhang et al., 2019). However, they focused on parents rather than mothers specifically. While both maternal and paternal substance use are considered significant risks for child maltreatment and neglect, mothers are usually the primary caregivers. As a result, they are more likely to be involved with child protection services and to manage the negative effects of their substance use from their children (Douglas \& Walsh, 2009). To date, only two reviews were conducted looking into the interventions that were designed to address the needs of mothers with substance use problems and how they could support family reunification outcomes (Doab et al., 2015; Murphy et al., 2017). While both reviews concluded that participation in integrated treatment programmes might increase the likelihood of reunification between mothers and their children, it is unclear if the integrated treatment programmes could reduce the risks of removal from mothers who were caring for dependent children. Furthermore, the findings from the two reviews were synthesised narratively. An objective estimate of the effectiveness of these programmes is needed to develop a comprehensive understanding on how they can better support mothers in retaining their rights to care for their children.

The primary objective of this review was to determine whether integrated treatment programmes for mothers with substance use problems were effective in reducing out-of-home child placement (temporally/permanent), when compared with control groups. The secondary objective was to explore the effectiveness of these programmes on other maternal factors that could influence the outcomes of the childcare proceedings, including 
patterns of substance use, treatment completion and parenting behaviours, such as managing parent-child conflict and child abuse risk.

\section{Methods}

A systematic review with meta-analysis was conducted in accordance with the Preferred Reporting Items for Systematic Review and Meta-Analyses Protocols (Moher et al., 2009). This protocol was registered with the International Prospective Register of Systematic Reviews (Neo et al., 2020; PROSPERO 2020, CRD42020184863)

\section{Eligibility}

The PICOS (Population, Interventions, Comparators, Outcomes, Study designs) was used to format the inclusion criteria (see Supplementary Materials Table S1 for detailed eligibility criteria). Citations were included if the full text articles were published in English. Studies were eligible if: (1) they included mothers with substance use problems of one or more children younger than 18 years old; (2) they used a controlled design involving either randomisation (i.e. randomised controlled trials (RCTs)) or non-randomised controlled studies with an appropriate comparator group, such as those not receiving any intervention or who took part in treatment-as-usual; (3) they used integrated treatment programmes broadly defined as comprehensive services that concurrently address substance use and other maternal needs through prenatal services, mental health services, parenting programmes, childcare, or other child-centred services; and (4) they included quantitative measures of the outcomes of childcare proceedings, including the loss or retention of care of the child, foster care, kinship care, residential care, and family reunification.

The review also considered secondary outcomes, including: (1) treatment completion as defined by the rate of participants' adherence or retention to the treatment programme, (2) maternal substance use as defined by the intake of illicit drugs or alcohol by the mothers measured after treatment, and (3) parenting behaviours, such as the mother's ability to manage conflicts with child or her attitudes and risk towards child abuse.

\section{Search Strategy}

The following databases were searched from inception to 1 March 2021: Cochrane Drugs and Alcohol Group Specialized Register, Cochrane Central Register of Controlled Trials (CENTRAL), CINHAL via Ecohost platform, EMBASE, MEDLINE and PsycINFO via OVID interface (see Supplementary Materials S2 for search terms).
Relevant citations were also sourced from the reference list of key papers and the 'grey' literature, including WorldCat and OpenGrey.

Identified citations from the search strategy were uploaded to Zotero 5.0.89 and the duplicates were removed manually. In cases where findings from technical reports (grey literature) were also published in peer-reviewed journal, only the peer-reviewed article was included. The full text of the remaining citations was retrieved and assessed according to the inclusion/exclusion criteria by two independent reviewers ( $\mathrm{SNe}$ and DK). Discrepancies were resolved by discussion and consensus. In the event that disagreements occurred regarding the inclusion of the studies, the final decisions were reached through referral to a third author.

\section{Data Extraction}

Using a standardised form, $\mathrm{SNe}$ extracted the relevant data and results of each study from the following areas: authors, publication year, country where the research was conducted, participants' characteristics, study design, interventions, and primary and secondary outcomes (Table 1).

\section{Quality Assessment}

Study quality was rated by two authors independently using the Cochrane Risk of Bias tool version 2 (RoB2, Sterne et al., 2019). The tool assesses five domains of study quality: randomisation; allocation concealment; blinding of participants, therapists, and outcome assessors; incomplete outcome data; and selective outcome reporting (Fig. 2). Each domain was scored according to whether there was high, moderate, or low risk of bias. Conflicting assessments were resolved through discussion. In addition to the RoB2, the Risk Of Bias in Non-randomised Studies - of Intervention (ROBINS-I) was used to evaluate the risk of bias for non-randomised studies (Sterne et al., 2016) from pre, during and post intervention (see Supplementary Materials Figure and Table S3 for ROBINS-I risk assessment).

\section{Statistical Analysis}

Effect sizes were calculated in terms of odds ratios $(O R)$ for dichotomous outcomes and standardised mean differences $(S M D)$ for continuous outcomes, with 95\% confidence interval (CI). The software program RevMan 5.4.1 (Review Manager (RevMan), n.d.) and an online calculator (Wilson, n.d.) were used to calculate the effect sizes. Where available, the effect sizes were calculated based on quantitative data analyses performed on an intent-to-treat basis for RCTs (Higgins, Li, et al., 2019) and on adjusted scores for non- 


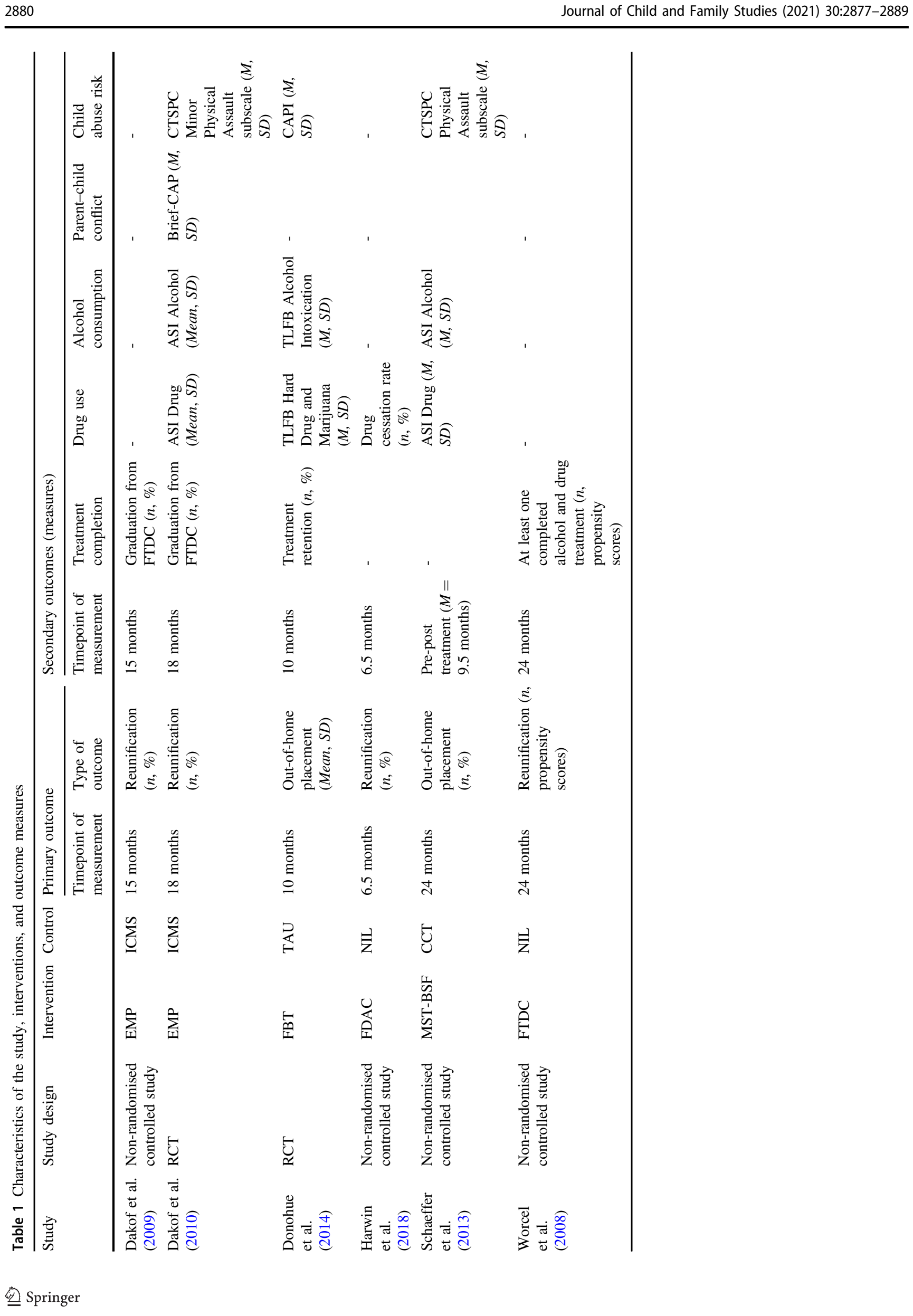


randomised controlled studies (Reeves et al., 2019). For studies that have multiple effect estimates of an outcome domain, a decision was made to either calculate an average of the effect estimates if the measures were assessed to be interchangeable, or to select the most relevant data from the most comparable time period of measurement and outcome measure (Higgins, Li, et al., 2019; McKenzie et al., 2019).

Heterogeneity was assessed by examining the clinical variability within the study and by calculating the statistical heterogeneity through the use of the chi-squared test and $I^{2}$ statistic (Brown \& Richardson, 2017). The chi-squared test was used to examine if the observed differences in the results were due to chance alone. The $I^{2}$ statistic was used to assess the impact of heterogeneity on the variability of effect estimates, where $I^{2}>30 \%$ may be indicative of moderate to substantial heterogeneity (Deeks \& Higgins, 2019).

A meta-analysis using the random-effects method was conducted on the outcomes. Generic inverse variance method was used to calculate the weighted average of the effect sizes in either $O R$ or SMD (Deeks et al., 2001). Forest plots with the pooled effect size were generated for each outcome using RevMan 5.4.1. When possible, exploratory subgroup analysis was conducted to identify the source of heterogeneity (Deeks \& Higgins, 2019).

\section{Results}

\section{Study Selection}

The search strategy from electronic databases and 'grey' literature revealed a total of 1369 and 494 citations respectively. After removing 564 duplicates, 1299 unique citations remained. The titles and abstracts were screened for their relevance and 80 citations were identified as potentially relevant. After full text screening by two authors (SNe and DK), 6 citations met the eligibility criteria and were included in the review (Fig. 1). There was a substantial agreement between the two reviewers ( $\mathrm{SNe}$ and $\mathrm{DK})$ on the final selection of papers (Cohen's kappa $=0.78,95 \% \mathrm{CI}=$ $0.54,1.02, p<0.001)$. Discrepancies were resolved by consensus between the two reviewers.

\section{Study Characteristics}

The final sample of six studies included two RCTs (Dakof et al., 2010; Donohue et al., 2014) and four non-randomised controlled studies (Dakof et al., 2009; Harwin et al., 2018; Schaeffer et al., 2013; Worcel et al., 2008). Although a controlled study, Schaeffer et al. (2013) reported some secondary outcomes as pre-post comparisons in the intervention group. Five studies were conducted in the United
States of America (USA) and one study was conducted in United Kingdom (UK), as described in Table 1.

The selected studies included a total of 1717 mothers with a history of substance use who were involved in the child welfare system. While four of the USA based studies recruited mothers from a family drug court or stategoverned family and child services department, Worcel et al. (2008) recruited mothers from three different stategoverned family drug courts in USA, resulting in a large sample size. Similarly, Harwin et al. (2018) recruited mothers from various local authorities within London, UK, who provided Family Drug and Alcohol Court (FDAC) services. The studies were characterised by participants with low education qualifications, lack of legal marital status, high rates of unemployment and lifetime history of physical abuse (see Supplementary Materials S4 Table for details on participants' characteristics for each study).

\section{Intervention Characteristics}

All the six studies combined substance use treatment services with related family-oriented services for both the mothers and their children. Dakof et al. (2009, 2010) used a multidimensional family therapy-based programme called Engaging Mothers Program (EMP) to motivate the mothers to attend their treatment and court sessions. An EMP-trained counsellor facilitated this change through a series of individual and family sessions, which targeted the mothers' motivation, commitment, problem solving, and parenting skills.

Donohue et al. (2014) adopted the Family Behaviour Therapy (FBT) in their programme, which focused on helping the mothers build necessary skills to manage their substance use and to improve their home environment and parenting practices, with support of their family members. FBT utilised multiple intervention components, including contingency management, communication skills training, stimulus control interventions, self-control method to manage drug cravings, and skills training specific to attaining employment.

Schaeffer et al. (2013) focused on Multisystemic Therapy Building Stronger Families (MST-BSF) programme, which is an adaptation of the Standard Multisystemic Therapy model (MST; Henggeler et al., 2009) for the context of child maltreatment and parental substance use. The MST-BSF teams provided comprehensive in-home treatment for families addressing the following areas: substance use, anger management, trauma and Post Traumatic Stress Disorder, family conflict, communication, and employment.

Worcel et al. (2008) focused on the American Family Treatment Drug Court (FTDC) model, a specialised court programme designed to reunify substance using families with their children through a range of services, which 
Fig. 1 PRISMA flow diagram

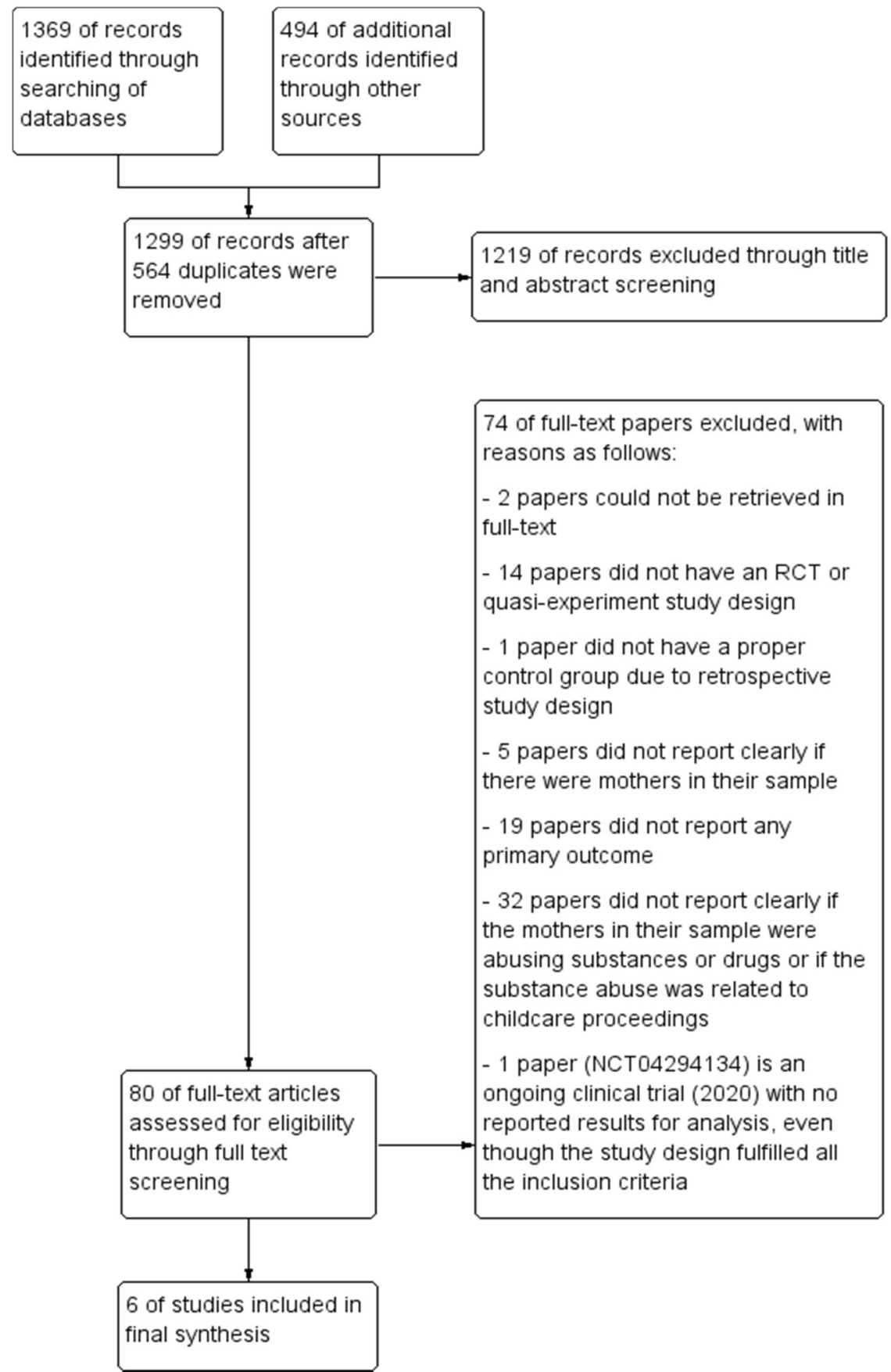

include intensive judicial monitoring, substance use assessment and referral, drug testing and other services provided through the collaborative drug court team. This model utilised a team of representatives from the court, child welfare and treatment systems, who worked together to monitor and support the mothers.

Relatedly, Harwin et al. (2018) focused on the London Family FDAC, which is an equivalent model of the American FTDC. FDAC offers judicial continuity and intensive treatment services for substance misuse and family support by a specialised multidisciplinary team. The only difference between the London FDAC and American FTDC is the length of care proceedings - FTDC is approximately one year, depending on the legislation of the country, while the FDAC is approximately six months, with possible length extension on a case-by-case basis.

\section{Quality Assessment}

Quality assessment (Fig. 2) revealed that the two RCTs were conducted with low risk of bias (Dakof et al., 2010; Donohue et al., 2014), but there was a lack of information 
Fig. 2 Risk of bias assessment for RCTs and non-randomised controlled studies using RoB 2
Fig. 3 Forest plot results for the subgroup analysis of RCTs and non-randomised controlled studies
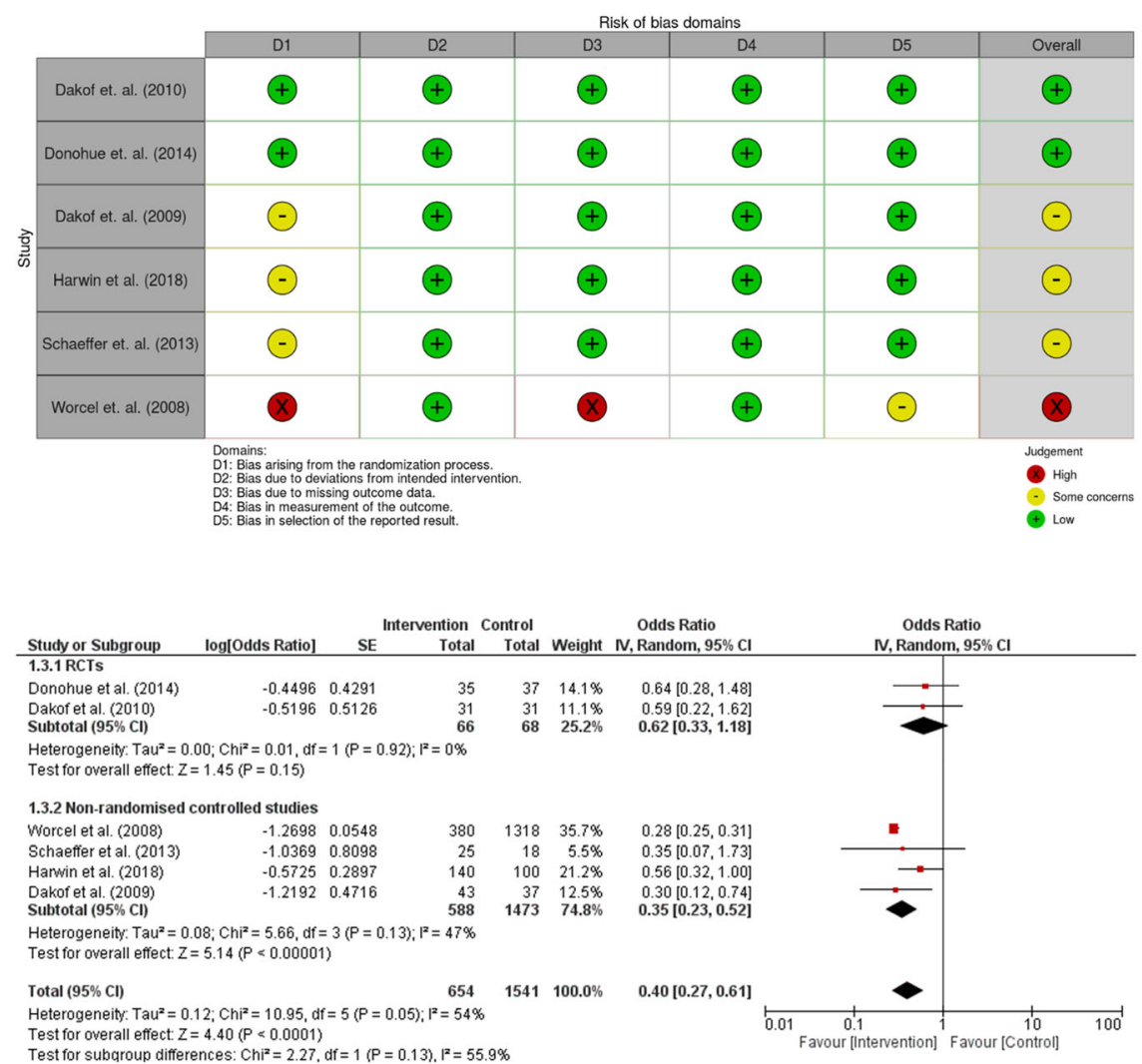

or clarity for some assessment domains. Specifically, while these RCTs did not explicitly state the allocation concealment process or the presence of a pre-determined protocol for independent analyses of results, there was evidence in both papers that proper randomisation using a software was conducted and that all of the outcomes' results were consistently reported (Page et al., 2019). Relatedly, the lack of masking of group allocation from the therapists and participants was assumed to have little impact on the risk of bias due to the nature of the interventions and the appropriate intent-to-treat analyses that were performed on the data (Higgins, Savović, et al., 2019).

Due to the lack of randomisation and potential selection of participants, particularly the matched control groups, the risk of bias was increased to at least a moderate level for all four non-randomised controlled studies (Dakof et al., 2009; Harwin et al., 2018; Schaeffer et al., 2013; Worcel et al., 2008). However, Worcel et al. (2008) was assessed to have a high risk of bias due to inequivalent groups at baseline, which indirectly introduced potential confounds to the study. Similarly, there were a number of missing outcome data from Worcel et al. (2008) study and the analytic plan appeared to be determined post data collection, leading to potential bias in the selection of reported results. There was a general agreement between RoB 2 and ROBINS-I in the quality assessment of the three non-randomised controlled studies (see Supplementary Materials S3 Figure and Table for details on ROBINSI risk assessment).

\section{Primary Outcome}

As there were repeated time observations of the primary and secondary outcomes across the studies, the data were extracted from the longest follow-up period, which were comparable across the studies. For the primary outcome, four studies reported their findings for child reunification (Dakof et al., 2009, 2010; Harwin et al., 2018; Worcel et al., 2008) and two studies reported findings for child's temporary out-of-home placement (Donohue et al., 2014; Schaeffer et al., 2013).

Mothers who participated in integrated treatment programmes, as compared to those who have not participated, were significantly less likely to lose the care of their children post-intervention $(O R=0.40,95 \% \mathrm{CI}=0.27,0.61$, $z=4.40, p<0.0001)$. Significant moderate statistical heterogeneity $\left(I^{2}=54 \%, p=0.05\right)$ was detected between the studies. Given that only six studies were included, this finding needs to be interpreted with caution (Fig. 3).

Exploratory subgroups analysis demonstrated that study design was a potential source of heterogeneity. Specifically, while the odds of losing the care of their children was 
Fig. 4 Forest plots for treatment completion (panel A), drug use (panel B), alcohol consumption (panel C), parent-child conflict (panel D) and child abuse risk (panel E)

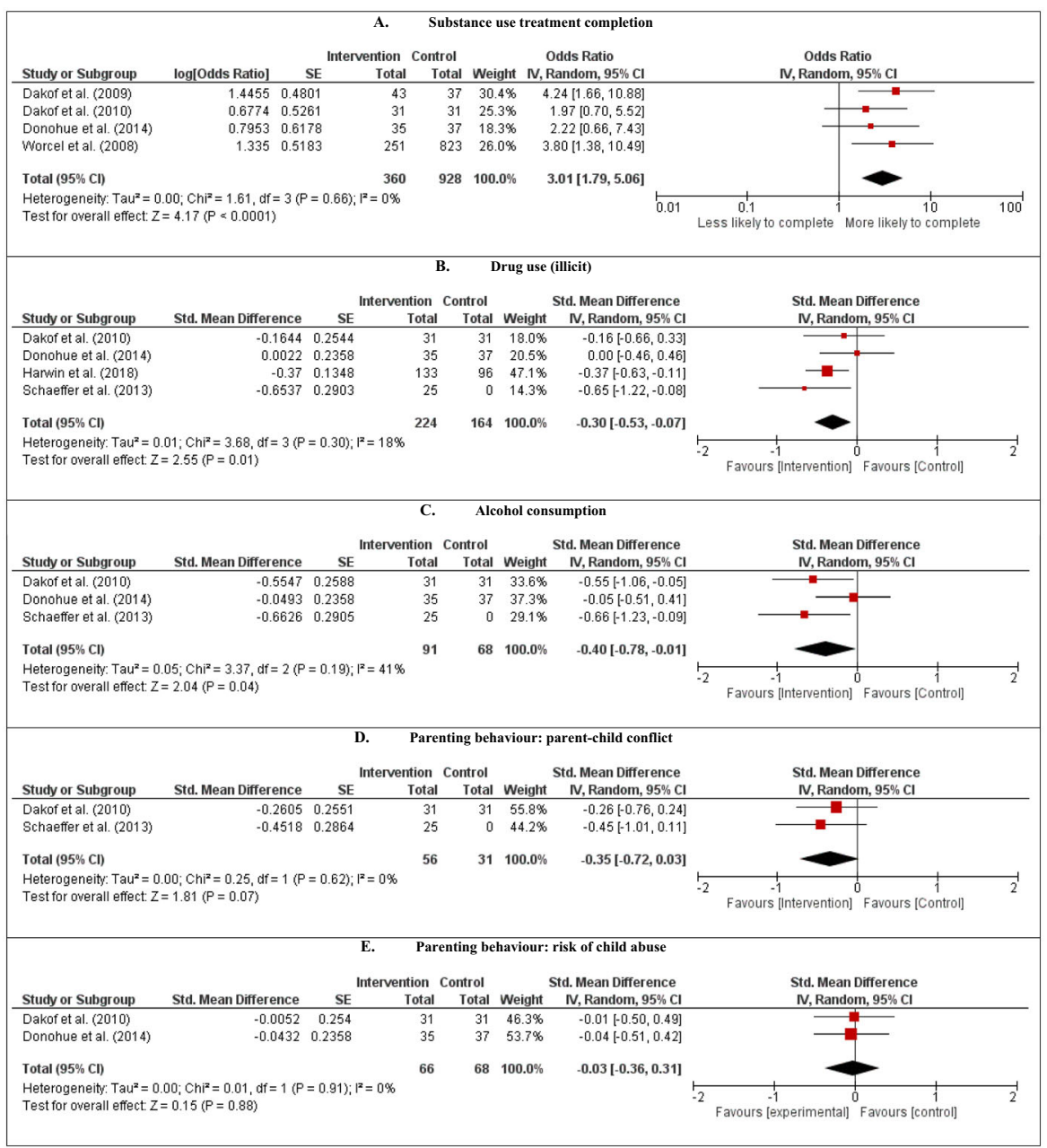

moderate for the mothers in the intervention groups, when compared to control groups, for RCTs ( $O R=0.62,95 \%$ $\mathrm{CI}=0.33,1.18, z=1.45, p=0.15)$, the effect was large and significant for non-randomised controlled studies $(O R$ $=0.35,95 \% \mathrm{CI}=0.23,0.52, z=5.14, p<0.00001)$.

\section{Secondary Outcomes}

For the secondary outcomes, four studies reported the rate of substance use treatment completion (Dakof et al., 2009, 2010; Donohue et al., 2014; Worcel et al., 2008); four studies reported the frequency of maternal drug use (Dakof et al., 2010; Donohue et al., 2014; Harwin et al., 2018; Schaeffer et al., 2013); three studies reported the frequency of alcohol consumption (Dakof et al., 2010; Donohue et al., 2014; Schaeffer et al., 2013); two studies reported findings on parent-child conflict (Dakof et al., 2010; Schaeffer et al., 2013); and two studies reported findings relating to child abuse risk (Dakof et al., 2010; Donohue et al., 2014). Table 1 describes the type of outcome measures for each study.

Of the four studies that assessed substance use treatment completion, the results demonstrated that mothers who participated in the integrated treatment programmes were significantly more likely to complete the treatment than those in the control groups (see Fig. 4 panel A; $O R=3.01$, $95 \% \mathrm{CI}=1.79,5.06, z=4.17, p<0.0001)$. No significant heterogeneity was detected $\left(I^{2}=0 \%, p>0.10\right)$.

With regards to the patterns of maternal substance use, the results demonstrated significant reductions in drug use $(S M D=-0.30, \quad 95 \% \quad \mathrm{CI}=-0.53, \quad-0.07, \quad z=2.55$, $p=0.01)$ and alcohol consumption $(S M D=-0.40,95 \%$ $\mathrm{Cl}=-0.78,-0.01, z=2.04, p=0.04)$ for mothers who participated in integrated treatment programmes, when compared with mothers in the control groups (see Fig. 4 panel B and C). Small to moderate $\left(I^{2}=18 \%\right.$ and $\left.41 \%\right)$ but non-significant statistical heterogeneity $(p=0.30$ and 0.19$)$ was observed for drug use and alcohol consumption, respectively. Due to limited number of studies for these outcomes, subgroup analyses were not conducted.

Of the two studies that assessed parenting behaviours, the results demonstrated a small treatment effect in reducing parent-child conflict $(S M D=-0.35,95 \% \mathrm{CI}=-0.72$, $0.03, z=1.81, p=0.07)$, but a negligible effect in reducing child abuse risk $(S M D=-0.03,95 \% \mathrm{CI}=-0.36,0.31$, 
$z=0.15, p=0.88$ ) for mothers who participated in the integrated treatment programmes, when compared with mothers in the control groups (see Fig. 4 panel D and E). However, both treatment effect sizes were not significant. No significant heterogeneity was detected $\left(I^{2}=0 \%\right.$, $p>0.10$ ).

\section{Discussion}

This systematic review and meta-analysis evaluated whether integrated treatment programmes for mothers with substance use problems reduced the likelihood of out-ofhome child placements and improved maternal factors that could influence the outcomes of childcare proceedings. Despite our broad inclusion criteria, only six studies were identified, of which five were conducted in the USA. Overall, the evidence from these studies is in favour of integrated treatment programmes. However, the small number and overall low methodological quality of the included studies limits the confidence with which firm conclusions can be drawn about the effectiveness of the programmes. Only two studies assessed the effects of the interventions on child placement outcomes using a randomised controlled trial design. Thus, the lack of rigorous scientific examination of the integrated treatment programmes hampers the effort of addressing the objectives of this review and suggests that presently these programmes are being utilised with unclear or unsupported benefit from a scientific standpoint. There is a clear and urgent need for adequately powered randomised controlled trials. Without further robust evaluative evidence, challenges will remain to demonstrate and persuade health and public policy on the far-reaching value of the integrated approaches.

In line with other reviews in the context of parental substance use and child welfare intervention research (Harwin et al., 2018; Zhang et al., 2019), our review demonstrates that the methodological quality of the studies has not improved over the years. The underpowered single centre trials impose important methodological limitations in this field as it is the reliance on retrospective administrative data for follow-up studies. One reason for the lack of robustly designed studies may be due to the difficulty and cost of randomised controlled trials. It is clear that greater investment is needed to overcome the methodological challenges of undertaking trials in this field. Researchers, social and health services, and commissioners must engage and develop collaborative strategies that could potentially increase research delivery capacity.

Out of the six studies included in this review, only two studies measured the effects of the interventions on child placement outcomes using a randomised controlled trial design. A wide difference in the treatment effects was also observed for randomised versus non-randomised controlled studies, for example, the odds ratio of out-of-home child placement post-treatment for studies using a randomised design was lower than what was observed from the odds ratio from non-randomised controlled studies. This suggests that the true estimate of the treatment effect may be closer to the lower value if more high quality randomised controlled studies were included in the review. Relatedly, the nature of the sample, which focused exclusively on mothers with a history of substance use problems who were involved in the child welfare system, may have influenced the magnitude of some of the significant effect sizes in this review. For instance, the effect size for treatment completion in this review is nearly to two times larger than the effect size observed in a review by Milligan et al. (2011), who examined the impact of integrated treatment programmes on treatment completion among mothers with substance use problems. The desire to attain the care of their child could have motivated the mothers to attend and complete treatment for their substance use (Jessup et al., 2003; Neger \& Prinz, 2015; Taplin \& Mattick, 2015), which may potentially inflate the effect size for treatment completion. Moreover, this review did not explore the possible impact of mothers' patterns of substance use (e.g., use of alcohol with/ without other types of illicit drugs) on child placement outcomes, despite the association between these two factors (Canfield et al., 2017). Further re-evaluation of the treatment effects is required by comparing the differences in treatment effects between mothers who were referred or not referred to the welfare system (Grella et al., 2009) and also between mothers who use alcohol in or not in combination with other types of drug use (Canfield et al., 2017). Such information is warranted to be able to inform who benefits from the integrated treatment programmes and under what type of circumstances.

Nevertheless, this review does provide an indication that mothers who participated in integrated treatment programmes were significantly less likely to have their children placed in out-of-home care (temporally/permanently) posttreatment, when compared with matched control groups who took part in treatment-as-usual or no intervention. In addition, integrated treatment programmes showed some potential in supporting mothers to complete treatment and in reducing their maternal substance use. These findings are in line with past reviews conducted on integrated treatment programmes in the context of parental substance use (Milligan et al., 2010, 2011; Moreland \& McRae-Clark, 2018; Niccols, Milligan, Sword, et al., 2012). Specifically, the FTDC/ FDAC model appears to be a useful paradigm in achieving family reunification and improving maternal outcomes for mothers with substance use problems in the USA and UK (Family Drug and Alcohol Court, n.d.; Harwin et al., 2014, 2016; Oliveros \& Kaufman, 2011; Zhang 
et al., 2019; Australia and Northern Ireland (Review Group, 2016)). Since FTDC integrates the criminal justice system with substance use treatment and relevant social services (e.g., employment, domestic violence intervention, and housing), the model is able to comprehensively address the multiple needs of the mothers, thereby supporting them in their recovery against substance use, child abuse and reentry to the welfare system (Doab et al., 2015; Murphy et al., 2017; Zhang et al., 2019). Relatedly, such collaboration between the services could allow quicker identification of mothers with early substance use problems, thereby providing them and their families with the relevant social services and potentially reducing their involvement in the childcare proceedings (Canfield et al., 2017). Having such specialised family courts that incorporate comprehensive health and social services may be the way forward in helping mothers with substance use problems during their childcare proceedings (Kerwin, 2005; Osterling \& Austin, 2008).

\section{Strengths and Limitations}

This systematic review and meta-analysis is the first review to consider the effectiveness of integrated treatment programmes on child placement outcomes for mothers with substance use problems. A high-quality methodology was used in this review and the findings could support further developments in the field of maternal substance use and child welfare.

The main limitation of this review is the low number of studies identified. The small sample of studies, coupled with the presence of non-randomised study designs, could only generate preliminary evidence on the effectiveness of the integrated treatment programmes. Additional subgroup analyses to compare the treatment effects across the studies and programme characteristics could not be performed. Relatedly, four of the six included studies used samples from the FTDC or FDAC model in the USA and UK respectively, and they explored only family reunification outcomes. It remains unclear if the impact of integrated treatment programmes could be generalised to other types of child placement outcomes (e.g., having their children in foster care), or to countries that do not adopt a FTDC/ FDAC model in supporting mothers with substance use problems.

\section{Conclusion}

While the findings from this review suggest that mothers who participated in integrated treatment programmes could potentially reduce the likelihood of out-of-home placements and improve maternal factors, the literature is not yet mature enough to demonstrate the far-reaching value of the integrated approaches. Thus, this review shows that presently integrated treatment programmes are being utilised with unclear or unsupported benefit from a scientific standpoint. More research, particularly high-quality RCTs, is required to add further supporting evidence to the field of maternal substance and child welfare.

\section{Compliance with Ethical Standards}

Conflict of Interest The authors declare no competing interests.

Publisher's note Springer Nature remains neutral with regard to jurisdictional claims in published maps and institutional affiliations.

Open Access This article is licensed under a Creative Commons Attribution 4.0 International License, which permits use, sharing, adaptation, distribution and reproduction in any medium or format, as long as you give appropriate credit to the original author(s) and the source, provide a link to the Creative Commons license, and indicate if changes were made. The images or other third party material in this article are included in the article's Creative Commons license, unless indicated otherwise in a credit line to the material. If material is not included in the article's Creative Commons license and your intended use is not permitted by statutory regulation or exceeds the permitted use, you will need to obtain permission directly from the copyright holder. To view a copy of this license, visit http://creativecommons. org/licenses/by/4.0/.

\section{References}

Basnet, S., Onyeka, I. N., Tiihonen, J., Föhr, J., \& Kauhanen, J. (2015). Characteristics of drug-abusing females with and without children seeking treatment in Helsinki, Finland. Scandinavian Journal of Public Health, 43(3), 221-228. https://doi.org/10. $1177 / 1403494814567754$.

Berger, L. M. (2005). Income, family characteristics, and physical violence toward children. Child Abuse \& Neglect, 29(2), 107-133. https://doi.org/10.1016/j.chiabu.2004.02.006.

Brown, M., \& Richardson, M. (2017). Understanding and synthesising numerical data from intervention studies. In Doing a systematic review-A student's guide. SAGE Publishing.

Canfield, M., Radcliffe, P., Marlow, S., Boreham, M., \& Gilchrist, G. (2017). Maternal substance use and child protection: a rapid evidence assessment of factors associated with loss of child care. Child Abuse \& Neglect, 70, 11-27. https://doi.org/10.1016/j.chia bu.2017.05.005.

Canfield, M., Norton, S., Downs, J., \& Gilchrist, G. (2021). Parental status and characteristics of women in substance use treatment services: analysis of electronic patient's records. Journal of Substance Abuse and Treatment, https://doi.org/10.1016/j.jsat. 2021.108365.

Chowdry, H. (2018). Estimating the prevalence of the 'toxic trio'. Evidence from the Adult Psychiatric Morbidity Survey (Vulnerability Technical Report 2). https://www.childrenscommissioner. gov.uk/wp-content/uploads/2018/07/Vulnerability-TechnicalReport-2-Estimating-the-prevalence-of-the-toxic-trio.pdf.

Dakof, G. A., Cohen, J. B., Henderson, C. E., Duarte, E., Boustani, M., Blackburn, A., Venzer, E., \& Hawes, S. (2010). A randomized pilot study of the engaging moms program for family drug court. Journal of Substance Abuse Treatment, 38(3), 263-274. https://doi.org/10.1016/j.jsat.2010.01.002. 
Dakof, G. A., Cohen, J. J. B., \& Duarte, E. (2009). Increasing family reunification for substance-abusing mothers and their children: comparing two drug court interventions in Miami. Juvenile and Family Court Journal, 60(4), 11-23. https://doi.org/10.1111/j. 1755-6988.2009.01033.x.

Deeks, J. J., Altman, D. G., \& Bradburn, M. J. (2001). Statistical methods for examining heterogeneity and combining results from several studies in meta-analysis. In M. Egger, G. D. Smith, \& D. G. Altman (Eds.), Systematic Reviews in Health Care (pp. 285-312). BMJ Publishing Group. https://doi.org/10.1002/ 9780470693926.ch15.

Deeks, J. J., \& Higgins, J. P. T. (2019). Chapter 10: Analysing data and undertaking meta-analyses. In D. G. Altman (Ed.), Cochrane Handbook for Systematic Reviews of Interventions version 6.0 (updated July 2019). (p. 45). Cochrane.

Doab, A., Fowler, C., \& Dawson, A. (2015). Factors that influence mother-child reunification for mothers with a history of substance use: a systematic review of the evidence to inform policy and practice in Australia. International Journal of Drug Policy, 26(9), 820-831. https://doi.org/10.1016/j.drugpo.2015.05.025.

Donohue, B., Azrin, N. H., Bradshaw, K., Van Hasselt, V. B., Cross, C. L., Urgelles, J., Romero, V., Hill, H. H., \& Allen, D. N. (2014). A controlled evaluation of family behavior therapy in concurrent child neglect and drug abuse. Journal of Consulting and Clinical Psychology, 82(4), 706-720. https://doi.org/10. 1037/a0036920.

Douglas, H., \& Walsh, T. (2009). Mothers and the child protection system. International Journal of Law, Policy Family, 23, 211-229. https://doi.org/10.1093/lawfam/ebp004.

Dutra, L., Stathopoulou, G., Basden, S. L., Leyro, T. M., Powers, M. B., \& Otto, M. W. (2008). A meta-analytic review of psychosocial interventions for substance use disorders. American Journal of Psychiatry, 165(2), 179-187. https://doi.org/10.1176/appi. ajp.2007.06111851.

Family Drug and Alcohol Court. (n.d.). National Website for Family Drug \& Alcohol Courts | FDAC. Retrieved 19 April 2021, from https://fdac.org.uk/.

Forrester, D., \& Harwin, J. (2007). Parental substance misuse and child welfare: outcomes for children two years after referral. British Journal of Social Work, 38(8), 1518-1535. https://doi.org/ 10.1093/bjsw/bcm051.

Gilchrist, G., \& Taylor, A. (2009). Drug-using mothers: factors associated with retaining care of their children: drug-using mothers. Drug and Alcohol Review, 28(2), 175-185. https://doi. org/10.1111/j.1465-3362.2008.00017.x.

Green, B. L., Rockhill, A., \& Furrer, C. (2007). Does substance abuse treatment make a difference for child welfare case outcomes? A statewide longitudinal analysis. Children and Youth Services Review, 29(4), 460-473. https://doi.org/10.1016/j.childyouth. 2006.08.006.

Grella, C. E., Hser, Y.-I., \& Huang, Y.-C. (2006). Mothers in substance abuse treatment: differences in characteristics based on involvement with child welfare services. Child Abuse \& Neglect, 30(1), 55-73. https://doi.org/10.1016/j.chiabu.2005.07.005.

Grella, C. E., Needell, B., Shi, Y., \& Hser, Y.-I. (2009). Do drug treatment services predict reunification outcomes of mothers and their children in child welfare? Journal of Substance Abuse Treatment, 36(3), 278-293. https://doi.org/10.1016/j.jsat.2008. 06.010 .

Harp, K. L. H., \& Oser, C. B. (2016). Factors associated with two types of child custody loss among a sample of African American mothers: a novel approach. Social Science Research, 60, 283-296. https://doi.org/10.1016/j.ssresearch. 2016.06.007.

Harwin, J., Alrouh, B., Broadhurst, K., McQuarrie, T., Golding, L., \& Ryan, M. (2018). Child and parent outcomes in the London family drug and alcohol court five years on: building on international evidence. International Journal of Law, Policy and The Family, 32, 140-169. https://doi.org/10.1093/lawfam/eby006.

Harwin, J., Alrouh, B., Ryan, M., Golding, L., Broadhurst, K., Tunnard, J., \& Swift, S. (2016). After FDAC: outcomes 5 years later Final Report (p. 89). Lancaster University. http://wp.lancs.ac.uk/ cfj-fdac/publications/.

Harwin, J., Alrouh, B., Ryan, M., \& Tunnard, J. (2014). Changing lifestyles, keeping children safe: an evaluation of the first Family Drug and Alcohol Court (FDAC) in care proceedings (p. 188). Brunel University.

Henggeler, S. W., Schoenwald, S. K., Borduin, C. M., Rowland, M. D., \& Cunningham, P. B. (2009). Multisystemic therapy for antisocial behavior in children and adolescents, Second Edition. Guilford Press.

Higgins, J. P., Li, T., \& Deeks, J. J. (2019). Chapter 6: Choosing effect measures and computing estimates of effect. In Cochrane Handbook for Systematic Reviews of Interventions version 6.0 (updated July 2019). (p. 36). Cochrane.

Higgins, J. P., Savović, J., Page, M. J., Elbers, R. G., \& Sterne, J. A. C. (2019). Chapter 8: Assessing risk of bias in a randomized trial. In Cochrane Handbook for Systematic Reviews of Interventions version 6.0 (updated July 2019). Cochrane. /handbook/current/ chapter-08.

Jessup, M. A., Humphreys, J. C., Brindis, C. D., \& Lee, K. A. (2003). Extrinsic barriers to substance abuse treatment among pregnant drug dependent women. Journal of Drug Issues, 33(2), 285-304. https://doi.org/10.1177/002204260303300202.

Kerwin, M. E. (2005). Collaboration between child welfare and substance-abuse fields: combined treatment programs for mothers*. Journal of Pediatric Psychology, 30(7), 581-597. https://doi.org/10.1093/jpepsy/jsi045.

Lieberman, L. D. (1998). Overview of substance abuse prevention and treatment approaches in urban, multicultural settings: The Center for Substance Abuse Prevention programs for pregnant and postpartum women and their infants. Women's Health Issues: Official Publication of the Jacobs Institute of Women's Health, 8 (4), 208-217. https://doi.org/10.1016/s1049-3867(98)00010-3.

Magura, S., \& Laudet, A. B. (1996). Parental substance abuse and child maltreatment: review and implications for intervention. Children and Youth Services Review, 18(3), 193-220. https://doi. org/10.1016/0190-7409(96)00001-1.

Marsh, J. C., \& Cao, D. (2005). Parents in substance abuse treatment: implications for child welfare practice. Children and Youth Services Review, 27(12), 1259-1278. https://doi.org/10.1016/j. childyouth.2005.01.002.

Marsh, J. C., Smith, B. D., \& Bruni, M. (2011). Integrated substance abuse and child welfare services for women: a progress review. Children and Youth Services Review, 33(3), 466-472. https://doi. org/10.1016/j.childyouth.2010.06.017.

McHugh, R. K., Hearon, B. A., \& Otto, M. W. (2010). Cognitivebehavioral therapy for substance use disorders. The Psychiatric Clinics of North America, 33(3), 511-525. https://doi.org/10. 1016/j.psc.2010.04.012.

McKenzie, J. E., Brennan, S. E., Ryan, R. E., Thomson, H. J., \& Johnston, R. V. (2019). Chapter 9: Summarizing study characteristics and preparing for synthesis. In Cochrane Handbook for Systematic Reviews of Interventions version 6.0 (updated July 2019). Cochrane. /handbook/current/chapter-09.

Messina, N., Calhoun, S., Conner, E., \& Miller, M. (2015). Improving the outcomes of children affected by parental substance abuse: a review of randomized controlled trials. Substance Abuse and Rehabilitation, 15. https://doi.org/10.2147/SAR.S46439.

Milligan, K., Niccols, A., Sword, W., Thabane, L., Henderson, J., \& Smith, A. (2011). Length of stay and treatment completion for mothers with substance abuse issues in integrated treatment 
programmes. Drugs: Education, Prevention and Policy, 18(3), 219-227. https://doi.org/10.3109/09687637.2010.511638.

Milligan, K., Niccols, A., Sword, W., Thabane, L., Henderson, J., Smith, A., \& Liu, J. (2010). Maternal substance use and integrated treatment programs for women with substance abuse issues and their children: a meta-analysis. Substance Abuse Treatment, Prevention, and Policy, 5(101258060), 21 https://doi. org/10.1186/1747-597X-5-21.

Moher, D., Liberati, A., Tetzlaff, J., \& Altman, D. G. (2009). Preferred reporting items for systematic reviews and meta-analyses: The PRISMA statement. BMJ, 339. https://doi.org/10.1136/bmj. b2535.

Moreland, A. D., \& McRae-Clark, A. (2018). Parenting outcomes of parenting interventions in integrated substance-use treatment programs: a systematic review. Journal of Substance Abuse Treatment, 89, 52-59. https://doi.org/10.1016/j.jsat.2018.03. 005 .

Murphy, A. L., Harper, W., Griffiths, A., \& Joffrion, C. (2017). Family reunification: a systematic review of interventions designed to address co-occurring issues of child maltreatment and substance use. Journal of Public Child Welfare, 11(4-5), 413-432. https:// doi.org/10.1080/15548732.2017.1340221.

Nair, P., Schuler, M. E., Black, M. M., Kettinger, L., \& Harrington, D. (2003). Cumulative environmental risk in substance abusing women: early intervention, parenting stress, child abuse potential and child development. Child Abuse \& Neglect, 27(9), 997-1017. https://doi.org/10.1016/S0145-2134(03)00169-8.

Neger, E. N., \& Prinz, R. J. (2015). Interventions to address parenting and parental substance abuse: conceptual and methodological considerations. Clinical Psychology Review, 39, 71-82. https:// doi.org/10.1016/j.cpr.2015.04.004.

Neo, S. H. F., Canfield, M., Norton, S., \& Kavallari, D. (2020). Effectiveness of psychosocial interventions on the outcomes of childcare proceedings for substance abusing mothers - a systematic review and meta-analysis. International Prospective Register of Systematic Reviews: PROSPERO 2020 CRD42020184863.

Niccols, A., Milligan, K., Sword, W., Thabane, L., Henderson, J., \& Smith, A. (2012a). Integrated programs for mothers with substance abuse issues: A systematic review of studies reporting on parenting outcomes. Harm Reduction Journal, 9, 14. https://doi. org/10.1186/1477-7517-9-14

Niccols, A., Milligan, K., Smith, A., Sword, W., Thabane, L., \& Henderson, J. (2012b). Integrated programs for mothers with substance abuse issues and their children: A systematic review of studies reporting on child outcomes. Child Abuse \& Neglect, 36, 308-322. https://doi.org/10.1016/j.chiabu.2011.10.007.

Oliveros, A., \& Kaufman, J. (2011). Addressing substance abuse treatment needs of parents involved with the child welfare system. Child Welfare, 90(1), 11.

Osterling, K. L., \& Austin, M. J. (2008). Substance abuse interventions for parents involved in the child welfare system. Journal of Evidence-Based Social Work, 5(1-2), 157-189. https://doi.org/ 10.1300/J394v05n01_07.

Page, M. J., Higgins, J. P. T., \& Sterne, J. A. C. (2019). Chapter 13: Assessing risk of bias due to missing results in a synthesis. In Cochrane Handbook for Systematic Reviews of Interventions version 6.0 (updated July 2019). Cochrane. /handbook/current/ chapter-13.

Porowski, A. W., Burgdorf, K., \& Herrell, J. M. (2004). Effectiveness and sustainability of residential substance abuse treatment programs for pregnant and parenting women. Evaluation and Program Planning, 27(2), 191-198. https://doi.org/10.1016/j.eva lprogplan.2004.01.008.

Public Health England. (2018, December). Safeguarding children affected by parental alcohol and drug use. GOV.UK. https://www.gov.uk/government/publications/safeguardingchildren-affected-by-parental-alcohol-and-drug-use.

Radcliffe, P., Canfield, M., Boreham, M., Marlow, S., \& Gilchrist, G. (2020). How to capture the experience of mothers with alcohol problems involved in English family court proceedings - lessons from the field. Advances in Dual Diagnosis, 13(1), 46-55. https:// doi.org/10.1108/ADD-11-2019-0015.

Rawson, R. A., \& Branch, C. (2002). Connecting substance abuse treatment and research: "Let's Make a Deal". Journal of Drug Issues, 32(3), 769-782. https://doi.org/10.1177/ 002204260203200303.

Rawson, R. A., Marinelli-Casey, P. \& Ling, W. (2002). Dancing with strangers: Will U.S. substance abuse practice and research organizations build mutually productive relationships? Addictive Behaviors, 9, 941-949.

Reay, W. E. (2010). Organizational adaptation: bridging the research to practice gap. Administration and Policy in Mental Health and Mental Health Services Research, 37(1-2), 95-99. https://doi. org/10.1007/s10488-010-0275-2.

Reeves, B. C., Deeks, J. J., Higgins, J. P. T., Shea, B., Tugwell, P., \& Wells, G. A. (2019). Chapter 24: Including non-randomized studies on intervention effects. In Cochrane Handbook for Systematic Reviews of Interventions version 6.0 (updated July 2019). (p. 27). Cochrane.

Review Manager (RevMan) (Version 5.4). (n.d.). [Computer software]. The Cochrane Collaboration, 2020.

Review Group (2016). Review of civil and family justice: the review group's draft report on family justice, August 4, 2016. Available from http://niopa.qub.ac.uk.

Sarkola, T., Kahila, H., Gissler, M., \& Halmesmäki, E. (2007). Risk factors for out-of-home custody child care among families with alcohol and substance abuse problems. Acta Paediatrica, 96(11), 1571-1576. https://doi.org/10.1111/j.1651-2227.2007.00474.x.

Schaeffer, C. M., Swenson, C. C., Tuerk, E. H., \& Henggeler, S. W. (2013). Comprehensive treatment for co-occurring child maltreatment and parental substance abuse: outcomes from a 24month pilot study of the MST-Building Stronger Families program. Child Abuse \& Neglect, 37(8), 596-607. https://doi.org/10. 1016/j.chiabu.2013.04.004

Smith, L. S., \& Wilkins, N. (2018). Mind the gap: approaches to addressing the research-to-practice, practice-to-research chasm. Journal of Public Health Management and Practice, 24, S6-S11. https://doi.org/10.1097/PHH.0000000000000667.

Sterne, J. A. C., Savović, J., Page, M. J., Elbers, R. G., Blencowe, N. S., Boutron, I., Cates, C. J., Cheng, H.-Y., Corbett, M. S., Eldridge, S. M., Emberson, J. R., Hernán, M. A., Hopewell, S., Hróbjartsson, A., Junqueira, D. R., Jüni, P., Kirkham, J. J., Lasserson, T., Li, T., ... Higgins, J. P. T. (2019). RoB 2: A revised tool for assessing risk of bias in randomised trials. BMJ, 14898. https://doi.org/10.1136/bmj.14898.

Sterne, J. A., Hernán, M. A., Reeves, B. C., Savović, J., Berkman, N. D., Viswanathan, M., Henry, D., Altman, D. G., Ansari, M. T., Boutron, I., Carpenter, J. R., Chan, A.-W., Churchill, R., Deeks, J. J., Hróbjartsson, A., Kirkham, J., Jüni, P., Loke, Y. K., Pigott, T. D., ... Higgins, J. P. (2016). ROBINS-I: A tool for assessing risk of bias in non-randomised studies of interventions. BMJ, i4919. https://doi.org/10.1136/bmj.i4919.

Sword, W., Jack, S., Niccols, A., Milligan, K., Henderson, J., \& Thabane, L. (2009). Integrated programs for women with substance use issues and their children: a qualitative meta-synthesis of processes and outcomes. Harm Reduction Journal, 6(1), 32 https://doi.org/10.1186/1477-7517-6-32.

Taplin, S., \& Mattick, R. P. (2013). Mothers in methadone treatment and their involvement with the child protection system: a replication and extension study. Child Abuse \& 
Neglect, 37(8), 500-510. https://doi.org/10.1016/j.chiabu.2013. 01.003 .

Taplin, S., \& Mattick, R. P. (2015). The nature and extent of child protection involvement among heroin-using mothers in treatment: high rates of reports, removals at birth and children in care. Drug and Alcohol Review, 34(1), 31-37. https://doi.org/10.1111/dar. 12165 .

Tracy, E. M. (1994). Maternal substance abuse: protecting the child, preserving the family. Social Work, 39(5), 534-540. https://doi. org/10.1093/sw/39.5.534.

Tsantefski, M., Humphreys, C., \& Jackson, A. C. (2014). Infant risk and safety in the context of maternal substance use. Children and Youth Services Review, 47, 10-17. https://doi.org/10.1016/j. childyouth.2013.10.021.

Wall-Wieler, E., Roos, L. L., Brownell, M., Nickel, N. C., \& Chateau, D. (2018). Predictors of having a first child taken into care at birth: a population-based retrospective cohort study. Child Abuse \& Neglect, 76, 1-9. https://doi.org/10.1016/j.chiabu.2017.09.033.
Williams, G., Tonmyr, L., Jack, S. M., Fallon, B., \& MacMillan, H. L. (2011). Determinants of maltreatment substantiation in a sample of infants involved with the child welfare system. Children and Youth Services Review, 33(8), 1345-1353. https://doi.org/10. 1016/j.childyouth.2011.04.015.

Wilson, D. B. (n.d.). Practical meta-analysis effect size calculator [Online calculator]. Campbell Collaboration. Retrieved 24 June 2020, from https://campbellcollaboration.org/research-resources/ effect-size-calculator.html.

Worcel, S. D., Furrer, C. J., Green, B. L., Burrus, S. W. M., \& Finigan, M. W. (2008). Effects of family treatment drug courts on substance abuse and child welfare outcomes. Child Abuse Review, 17 (6), 427-443. https://doi.org/10.1002/car.1045.

Zhang, S., Huang, H., Wu, Q., Li, Y., \& Liu, M. (2019). The impacts of family treatment drug court on child welfare core outcomes: a meta-analysis. Child Abuse \& Neglect, 88, 1-14. https://doi.org/ 10.1016/j.chiabu.2018.10.014. 